\title{
Caracterización del uso inapropiado de antibióticos en faringoamigdalitis según los criterios de Mclsaac
}

\author{
Characterization of inappropiate use of antibiotics on pharyngoamygdalitis according to \\ Mclsaac's criteria
}

\section{Caracterização do uso indevido de antibióticos em faringotonsilite de acordo com os critérios do Mclsaac}

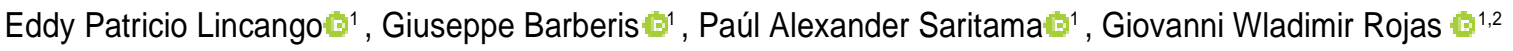 \\ ${ }^{1}$ Universidad Central del Ecuador (UCE). Quito, Ecuador. \\ ${ }^{2}$ Universidade de Sao Paulo (USP). São Paulo, SP, Brasil.
}

\section{Resumen}

Objetivo: Describir el uso irracional de antibióticos en base a criterios de Mclsaac (criterios de Centor modificados por Mclsaac), en una unidad de salud de primer nivel de atención. Métodos: Se realizó un estudio descriptivo transversal con los registros de pacientes de 3 a 19 años atendidos en el servicio de emergencia (246), con los diagnósticos de faringitis aguda, amigdalitis aguda, e infecciones respiratorias superiores agudas de múltiples sitios y sin especificar. Se estableció como prescripción inadecuada si el facultativo indicó antibióticos con un puntaje menor o igual a 1 sobre 5 puntos o si no prescribió antibióticos con puntaje mayor o 4 sobre 5 puntos. Resultados: Se estimó $24,29 \%$ de uso inadecuado de antibióticos de los registros de emergencia. Se prescribió antibióticos en 160 pacientes, de los cuales se encontró que, amoxicilina fue el más utilizado $(61,87 \%)$; seguido de benzilpenicilina benzatina $(28,12 \%)$ y en tercer lugar macrólidos (8,12\%). Conclusión: En la unidad de primer nivel analizada se encontró que el uso inadecuado de antibióticos es superior a la prevalecía estimada de faringoamigdalitis estreptocócica para el grupo de edad estudiado. Por esto, es imperativo que se tomen las medidas necesarias a nivel institucional y comunitario para lograr su reducción y evitar las complicaciones que se derivan de esta.

Palabras clave: Prescripción Inadecuada; Infecciones Estreptocócicas; Faringitis; Tonsilitis;

Utilización de Medicamentos

Cómo citar: Lincango EP, Barberis G, Saritama PA, Rojas GW. Caracterización del uso inapropiado de antibióticos en faringoamigdalitis según los criterios de Mclsaac. Rev Bras Med Fam Comunidade. 2019;14(41):2025. https://doi.org/10.5712/rbmfc14(41)2025

\section{Autor correspondiente: Eddy Patricio Lincango. E-mail: eddylin@live.com Financiación: ninguna declarada. Aprobación ética: no aplicable.}

Procedencia y revisión por pares: revisado por pares. Recibido el: 10/03/2019. Aceptado el: 28/08/2019. 


\begin{abstract}
Objective: To describe the irrational use of antibiotics based on Mclsaac criteria (Centor criteria modified by Mclsaac), in a primary care facility. Methods: A cross-sectional descriptive study was conducted with the medical record of patients from 3 to 19 years old, treated in the emergency department (246), with the diagnoses of acute pharyngitis, acute tonsillitis, and acute upper respiratory infections from multiple sites and not specified. It was established as an inappropriate prescription if the physician indicated antibiotics with a score less than or equal to 1 out of 5 points or if he did not prescribe antibiotics with a score greater than or equal to 4 out of 5 points. Results: Inadequate use of antibiotics was found in $24.29 \%$ of emergency records. Antibiotics were prescribed in 160 patients, of which, amoxicillin was the most used (61.87\%); followed by benzathine penicillin $(28.12 \%)$ and in third place macrolides (8.12\%). Conclusion: In the first level unit analyzed, it was found that the inappropriate use of antibiotics is superior to the estimated prevalence of streptococcal pharyngitis for the age group studied. Therefore, it is imperative that the necessary measures are taken at the institutional and community level to achieve its reduction and avoid the complications that result from it.
\end{abstract}

Keywords: Mclsaac criteria, Inappropriate Prescribing; Streptococcal Infections; Pharyngitis; tonsillitis; Drug Utilization

\title{
Resumo
}

Objetivo: Descrever o uso irracional de antibióticos com base nos critérios de Mclsaac (critérios de Centor modificados por Mclsaac), em uma unidade de saúde de primeiro nível de atenção. Métodos: Foi realizado um estudo descritivo transversal com os prontuários de pacientes de 3 a 19 anos atendidos no serviço de emergência (246), com diagnóstico de faringite aguda, amigdalite aguda, e infecções respiratórias superiores agudas de múltiplos locais e sem especificação. Estabeleceu-se como uma prescrição inadequada se o médico indicou antibióticos com um escore menor ou igual a 1 de 5 pontos ou se ele não prescreveu antibióticos com um escore maior ou igual a 4 de 5 pontos. Resultados: 0 uso inadequado de antibióticos foi estimado em $24,29 \%$ dos prontuários de emergência. Antibióticos foram prescritos em 160 pacientes, dos quais constatou-se que a amoxicilina foi a mais utilizada $(61,87 \%)$; em segundo, a penicilina benzatina $(28,12 \%)$; e, em terceiro lugar, os macrolídeos $(8,12 \%)$. Conclusão: Na unidade de primeiro nível analisada foi encontrado que o uso de antibióticos é superior à prevalência de faringite estreptocócica estimada para a faixa etária estudada. Então, é imperativo que a nível institucional e comunitário sejam tomadas as medidas necessárias para sua redução e evitar as complicações resultantes.

Palavras-chave: Critérios Mclsaac, Prescrição Inadequada; Infecções Estreptocócicas; Faringite; Tonsilite; Uso de Medicamentos

\section{Introducción}

El uso irracional de antibióticos sea por su cantidad (dosis subóptimas) o calidad (antibiótico inadecuado para la afección), conlleva a situaciones alarmantes como el aumento de la resistencia bacteriana, tasas terapéuticas y costos de los tratamientos. ${ }^{1}$ Se considera que entre el $20 \%$ al $50 \%$ de antibióticos se están utilizando de manera inapropiada en las infecciones del tracto respiratorio superior. ${ }^{2}$ Las recomendaciones que el Centro de Control y Prevención de Enfermedades (CDC, por sus siglas en inglés) ha propuesto para mejorar el uso de antimicrobianos en pacientes ambulatorios son las siguientes: compromiso en el mejoramiento de la prescripción de antibióticos y la seguridad del paciente; implementación de por lo menos una política o práctica en este ámbito; rastreo y reporte de las prácticas de prescripción de antimicrobianos y proveer de educación tanto a médicos como a pacientes acerca de la prescripción de antimicrobianos. ${ }^{3}$

Entre las infecciones que usualmente se deberían tratar sin antibióticos tenemos a las infecciones de tracto respiratorio superior, bronquitis, otitis media y muchos rashes de la piel. ${ }^{4}$ Este problema no puede ser prevenido, pero sí, disminuido; actuando sobre los factores que influyen en esta prescripción como son: los pensamientos y demandas del paciente; el juicio clínico del prescriptor, las políticas locales existentes y la capacidad de conseguir libre compra de antibióticos. ${ }^{5}$

La mayoría de las infecciones adquiridas en la comunidad son causadas principalmente por virus, autolimitadas en su evolución clínica y no requieren tratamiento antibiótico. ${ }^{6}$ A pesar de que el conocimiento de la poca implicación de organismos bacterianos en las infecciones del tracto respiratorio superior, el tratamiento antibacteriano para infecciones virales sigue tan popular como siempre. ${ }^{7} \mathrm{En}$ 
revisiones sistemáticas por parte de la colaboración Cochrane no se ha encontrado beneficio de antibióticos para el tratamiento del resfriado común, otitis media en niños, sinusitis maxilar, dolor de garganta y bronquitis aguda; además el número de pacientes que se necesita tratar para evitar las complicaciones que conllevan la infecciones de tracto respiratorio superior es mayor de 4000, mientras que los efectos adversos de los antimicrobianos usados para estas afecciones son mucho más comunes. ${ }^{7}$

La prevalencia de infecciones por Estreptococo beta hemolítico del grupo A (SBHGA) ocurre en $10 \%$ de adultos y hasta un 20 a $40 \%$ en niños; siendo el agente etiológico más prevalente en infecciones de origen bacteriano, las cuales son las únicas infecciones del tracto respiratorio superior que ameritan tratamiento antimicrobiano (exceptuando también las infecciones por Neisseria y Diphteria). ${ }^{8}$ Por este motivo se ha vuelto indispensable la estandarización del manejo en estos pacientes. Se han creado varias guías para el manejo de las infecciones del tracto respiratorio superior, en la cuales estandarizan el método de atención a los pacientes mediante criterios diagnósticos, su interpretación adecuada brinda una base para el adecuado manejo clínico. Entre las puntuaciones usadas podemos mencionar a los criterios de Centor, los criterios de Mclsaac (Centor modificado), FeverPAIN, Wald, Attia, etc. ${ }^{9}$

En este estudio se decidió emplear los Criterios de Mclsaac, ya que ha demostrado reducir en un $48 \%$ la prescripción de antibióticos en aquellos pacientes donde su uso no era necesario; ${ }^{10}$ por otro lado, una especificidad y sensibilidad del $67,2 \%$ y $83,1 \%$ respectivamente. La correlación con el test rápido de detección de antígeno es del $52 \%$, lo cual lo convierte en una herramienta diagnóstica útil. ${ }^{11}$

Los criterios de Mclsaac establecen 3 categorías. ${ }^{12}$ Todo esto acorde al puntaje calculado en base a una evaluación clínica que incluye: presencia de adenopatías cervicales dolorosas, fiebre $>38^{\circ} \mathrm{C}$, exudado peri amigdalino, edad comprendida entre los 3 y 14 años, ausencia de tos ${ }^{8}$ (Figura 1).

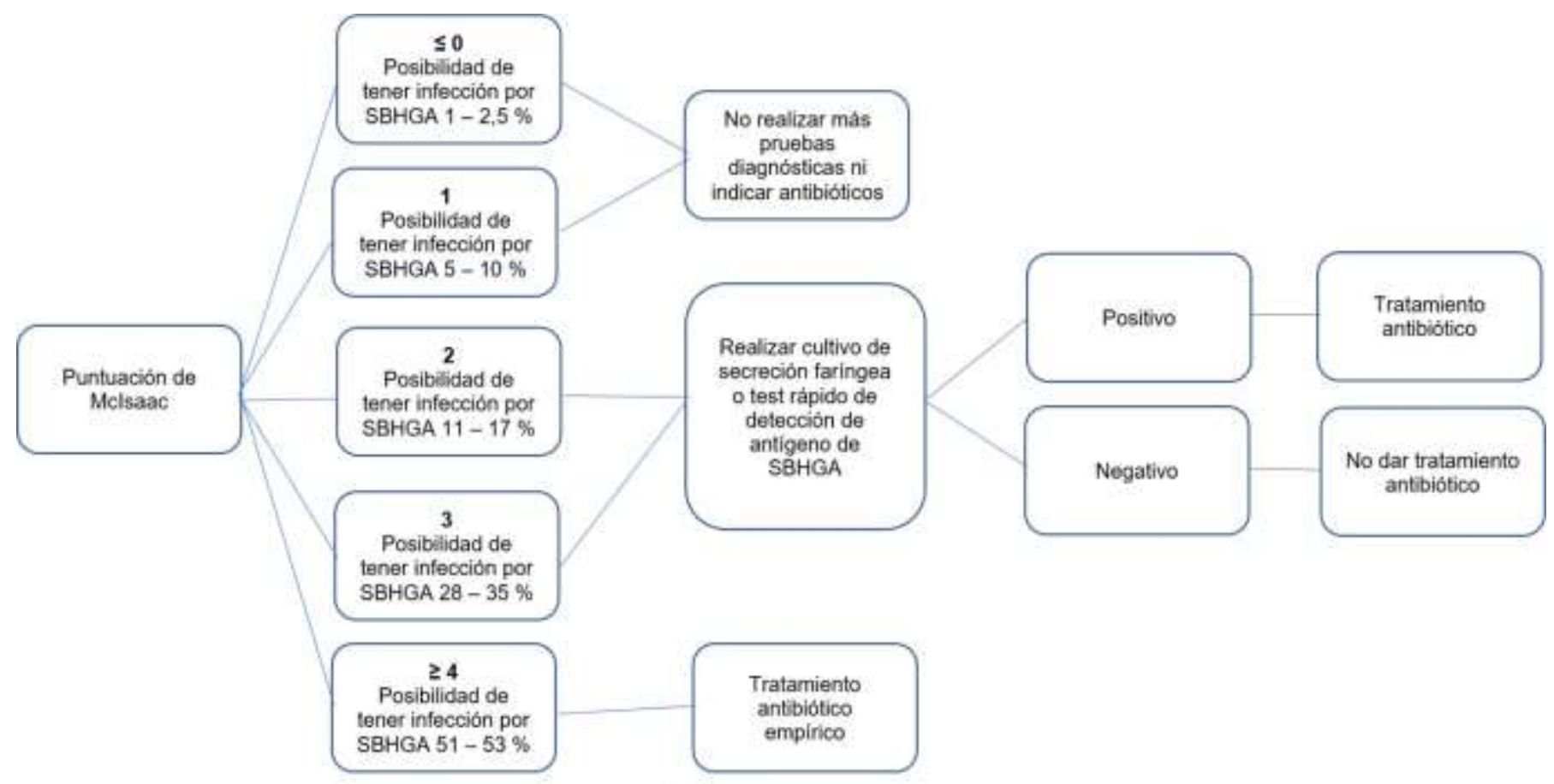

Figura 1. Algoritmo de manejo para los pacientes con faringitis en base a los criterios de Mclsaac.

Modificado de: Gutiérrez D, León K, Bahamonde H. Faringoamigdalitis estreptocócica. Rev Hosp Clín Univ Chile. 2011;22(6):281-8. 12 
Actualmente en Ecuador, específicamente en la ciudad de Quito, a nivel de atención primaria no se cuenta con una prueba para la determinación de $S$. pyogenes, la cual es parte fundamental para la correcta categorización de los pacientes con sospecha de infección por SBHGA. Por lo que en este estudio se ha planteado describir el uso irracional de antibióticos, únicamente con criterios clínicos, en un centro de salud de primer nivel de atención. ${ }^{13}$

\section{Materiales y Métodos}

En el periodo comprendido entre enero y julio de 2016 se registraron un total de 1801 consultas por problemas respiratorios en el servicio de emergencia de esta unidad de primer nivel de atención. Se seleccionó una muestra aleatoria de 246 pacientes de 3 a 19 años, en base a la prevalencia del menor factor de riesgo (20\%), diagnósticos con los códigos, según la Clasificación Internacional de Enfermedades 10ª edición, de faringitis aguda (CIE 10: J02, incluyendo J02.0, J02.8, J02.9), amigdalitis aguda (CIE 10: J03, incluyendo J03.0, J03.8, J03.9) e infecciones respiratorias superiores agudas de múltiples sitios y sin especificar (CIE 10: J06, incluyendo J06.0, J06.8, J06.9).

Se incluyeron los CIE 10: J06.8 y J02.8 porque hemos visto que durante la práctica clínica diaria, los médicos no usan correctamente los códigos CIE 10, por lo que puede haber pacientes diagnosticados con faringoamigdalitis por SBHGA en el grupo de estos códigos. Se excluyeron pacientes que tuvieron exposición a antibióticos en la semana previa a su atención, con inmunosupresión, aquellos que presentaron otros cuadros que justificaron el uso de antibióticos distintos a los mencionados y los registros médicos con datos incompletos. Se tomó en cuenta solo la primera atención por estos diagnósticos en cada paciente, no se consideraron visitas subsecuentes. Los datos se obtuvieron de registros, historias clínicas y prescripciones de los formularios respectivos. Los datos fueron recogidos personalmente por todos los investigadores utilizando una matriz de Excel 2013.

La principal variable de este estudio fue la prescripción adecuada de antibióticos en base a los criterios de Mclsaac. Se estableció como prescripción inadecuada si el facultativo indicó antibióticos con un puntaje menor o igual a 1 sobre 5 puntos o si no prescribió antibióticos con puntaje superior o igual a 4 de 5 puntos. Se definió como grupo de riesgo bajo de infección bacteriana al estrato con 0-1 punto, riesgo intermedio al estrato con 2-3 puntos y riesgo alto al estrato con 4-5 puntos según los criterios de Mclsaac. En los pacientes de riesgo intermedio, la prescripción de antibióticos no fue evaluada, debido al hecho de que en los servicios de atención primaria del Ministerio de Salud Pública del Ecuador, no se dispone de pruebas microbiológicas. Otras variables analizadas fueron: antibióticos usados y terapias coadyuvantes. Se decidió la división en 2 estratos de edad (Tabla 1) ya que, de acuerdo al estudio realizado por Mclsaac se estableció que la prevalencia de faringoamigdalitis estreptocócica era mayor en la población de 3 a 14 años de edad y menor en la población correspondiente a 15 a 19 años. ${ }^{10}$

Para el análisis estadístico se utilizó el software SPSS versión 18 con un intervalo de confianza del $95 \%$ y un error de inferencia del $5 \%$. Se usaron medidas estadísticas descriptivas acorde a la naturaleza de las variables, porcentajes, frecuencias, y medidas de asociación.

Para la realización de este estudio se contó con la aprobación del Coordinador de la Cátedra de Farmacología de la Universidad Central del Ecuador y de la Directora de la Unidad de Salud donde se 
llevó a cabo esta investigación. En Ecuador para la realización de estudios observacionales sin muestras biológicas, no se requiere aprobación de un comité de ética en investigación. ${ }^{14}$ Se guardó absoluta confidencialidad de los datos. Para analizar la asociación entre variables se utilizó la razón de prevalencia.

\section{Resultados}

Según nuestros hallazgos y baseados en los criterios de Mclsaac, el estrato en el cual se prescribió mayor número de antibióticos fue el de riesgo intermedio (48,7\%). El número de hombres y mujeres en el estudio fue el mismo (50\%) y el rango de edad del que se obtuvieron mayor número de registros fue entre 3 a 14 años (82,5\%). La mayor parte de participantes se encontró en el grupo de riesgo intermedio según los criterios de Mclsaac (71,5\%) (Tabla 1).

Tabla 1. Distribución del grupo de estudio según criterios de Mclsaac, uso de antibiótico, edad y sexo, en el centro de primer nivel en el periodo enero-julio 2016.

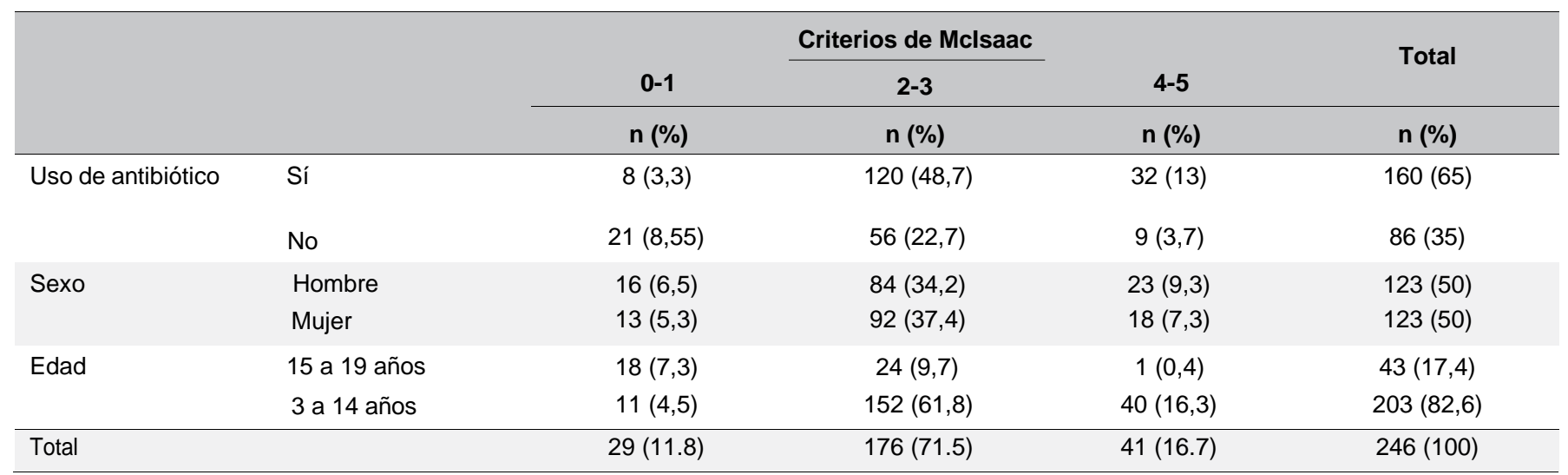

Elaboración: Los autores.

En cuanto a la prescripción de antibióticos de acuerdo con los criterios de Mclsaac, se encontró $27,6 \%$ de uso inadecuado en el grupo de bajo riesgo y un $22 \%$ en el grupo de alto riesgo; con una razón de prevalencia de 1,26 y un intervalo de confianza al 95\% de 0,55 - 2,87 (Tabla 2).

Tabla 2. Uso inadecuado de antibióticos en los pacientes diagnosticados con faringitis, amigdalitis o faringoamigdalitis aguda, en relación a riesgo bajo de infección bacteriana (puntaje 0-1) y alto riesgo de infección bacteriana (4-5); en el centro de primer nivel en el periodo enero-julio 2016.

\begin{tabular}{|c|c|c|c|c|c|c|}
\hline & & \multicolumn{3}{|c|}{$\begin{array}{c}\text { Criterios de } \\
\text { Mclsaac }\end{array}$} & \multirow{3}{*}{$\begin{array}{c}\text { Razón de } \\
\text { prevalencia }\end{array}$} & \multirow{3}{*}{$\begin{array}{c}\text { Intervalo de } \\
\text { confianza }\end{array}$} \\
\hline & & Bajo riesgo (0-1) & Alto riesgo (4-5) & Total & & \\
\hline & & n (\%) & n (\%) & n (\%) & & \\
\hline \multirow[t]{2}{*}{ Uso inadecuado } & Sí & $8(27,6)$ & $9(22)$ & $17(24,3)$ & 1.26 & $0.55-2.87$ \\
\hline & No & $21(72,4)$ & $32(78)$ & $53(75,7)$ & & \\
\hline
\end{tabular}

Elaboración: Los autores.

En relación con la prescripción inadecuada de acuerdo al sexo, se demostró uso inadecuado global en el $24,3 \%$ y por grupos se encontró $30,7 \%$ de uso inadecuado de antibióticos en el sexo masculino y un $16,1 \%$ en el sexo femenino; con una razón de prevalencia intrasexo de 1,91 y un intervalo de confianza al $95 \%$ de $0,75-4,84$ (Tabla 3 ). 
Tabla 3. Uso inadecuado de antibióticos en los pacientes diagnosticados con faringitis, amigdalitis o faringoamigdalitis aguda, en relación al sexo, en el centro de primer nivel en el periodo enero-julio 2016.

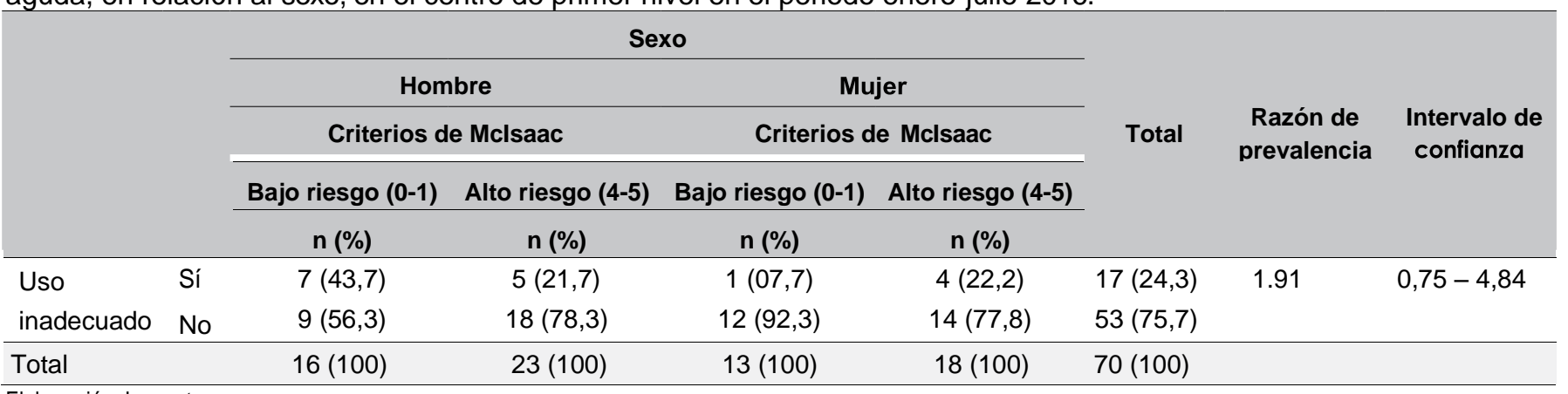

Elaboración: Los autores.

Del total (246 pacientes), se prescribió antibióticos en 160 pacientes, de los cuales se encontró que, amoxicilina fue el más utilizado $(61,87 \%)$; seguido de penicilina benzatínica $(28,1 \%)$ y en tercer lugar, macrólidos (8,2\%) (Tabla 4).

Tabla 4. Antibióticos usados en los pacientes diagnosticados con faringitis, amigdalitis o faringoamigdalitis aguda, en el centro de primer nivel en el periodo enero- julio 2016.

\begin{tabular}{lcc} 
& Antibiótico usado & \\
\hline Antibiótico & Frecuencia & Porcentaje \\
\hline Amoxicilina & 99 & 61,8 \\
Penicilina Benzatínica & 45 & 28,1 \\
Azitromicina & 13 & 8,2 \\
Cefalexina & 3 & 1,9 \\
\hline Total & 160 & 100,0 \\
\hline
\end{tabular}

Elaboración: Los autores.

En los tratamientos coadyuvantes se observó que los más prescriptos fueron paracetamol $(57,3 \%)$ y antiinflamatorios no esteroides en un (42,7\%), del cual el primer lugar corresponde a ibuprofeno $(36,2 \%)$ por vía oral, seguido de diclofenaco $(2,75 \%)$ y ketorolaco $(0,78 \%)$ los cuales fueron prescritos por vía parenteral (intramuscular) (Tabla 5).

Tabla 5. Analgésicos usados en los pacientes diagnosticados con faringitis, amigdalitis o faringoamigdalitis aguda, en el centro de primer nivel en el periodo enero-julio 2016.

\begin{tabular}{lcc}
\hline Medicamento & Frecuencia & Porcentaje \\
\hline Paracetamol & 141 & 57,3 \\
Ibuprofeno & 89 & 36,2 \\
Diclofenaco & 7 & 2,8 \\
Ketorolaco & 2 & 0,8 \\
\hline Total & 246 & 100,0 \\
\hline
\end{tabular}

Elaboración: Los autores. 


\section{Discusión}

Los resultados principales del estudio encontrados en el centro de salud de primer nivel de atención han sido: uso inadecuado de antibióticos en el $24,3 \%$ de los registros de emergencia y $27,6 \%$ de uso inadecuado de antibióticos en el grupo de bajo riesgo para el diagnóstico de faringoamigdalitis según los criterios de Mclsaac (Tabla 2). El grupo farmacológico más usado han sido los beta-lactámicos en un $87,5 \%$ y el analgésico que más se prescribió fue paracetamol en el 58,43\% de los casos. Se encontró que hay mayor posibilidad de uso inapropiado de antibióticos en el grupo de más bajo riesgo y en el sexo masculino, sin embargo la fuerza de esta afirmación es inconsistente.

Una limitación del estudio es el diseño, pues al ser de carácter transversal no se puede obtener una relación causal. Además, dada la extracción retrospectiva de la mayoría de los datos y la premura de la atención en el servicio de emergencia, los pacientes podrían haberse clasificado erróneamente según la codificación CIE 10, en una categoría incorrecta. Es por eso que en este estudio hemos usado J06.8 y J02.8 porque encontramos paciente diagnosticados con faringoamigdalitis por SBHGA en el grupo del cogido J06.8 y J02.8.

Cabe la pena mencionar que el número limitado de muestra que se obtuvo para el cálculo del uso inadecuado de antibióticos (puntajes 0-1 y 4-5), podría sesgar los intervalos de confianza obtenidos; puesto que la mayoría de individuos pertenecía al estrato de riesgo intermedio, en los cuales la actitud clínica más apropiada hubiera sido realizar una prueba de antígeno rápido o cultivo de faringe para el uso de antibiótico y no dejar esta decisión bajo el criterio clínico del médico. Entre sus fortalezas podemos mencionar que es el primer estudio realizado con esta modalidad en la población ecuatoriana y enfocándose en el primer nivel de atención.

Según estadistas nacionales, en la población ecuatoriana, de las 10.073 .573 atenciones registradas en las unidades de primer nivel en el año 2016, se evidenció que: 2.353 .403 (23,36\%) correspondieron a infecciones respiratorias altas (IRA) (códigos CIE-10: J00, J039, J029, J030, J020, J069). De todas las IRA, 178.071 atenciones fueron descritas como causadas por SBHGA (códigos J02.0, J03.0), justificándose el uso de antibióticos solamente en este grupo $(7,57 \%) ;{ }^{15}$ ya que, varios estudios han demostrado la ineficacia del uso de antibióticos en etiología viral. ${ }^{16}$ Existen pocos estudios ecuatorianos $^{18,17}$ sobre faringoamigdalitis y estos carecen de fortaleza estadista y poseen fallas metodológicas ${ }^{19,18}$. Es por eso que nos hemos adherido a las estadísticas nacionales para dar nuestro veredicto. En nuestro estudio, el uso inadecuado de antibióticos se refleja al ver que en el grupo de bajo riesgo de infección por el SBHGA se siguen prescribiendo antibióticos (27.6\%), a pesar de la baja prevalencia de esta infección bacteriana, y aún más la baja incidencia de sus complicaciones supurativas y no supurativas. Estos puede incurrir en altas tasas de resistencia a antibióticos e incluso, en un aumento de atenciones por efectos adversos relacionados a antibióticos. ${ }^{7}$

Acorde a la "Guía de práctica clínica para el diagnóstico y tratamiento de la faringitis estreptocócica del grupo A" de la IDSA, se recomienda que los pacientes con faringitis aguda por SBHGA deben tratarse con penicilina o amoxicilina, pero de preferencia penicilina (benzatínica o V), ya que, sigue siendo el tratamiento 
de elección por su eficacia, seguridad probadas, su espectro de acción reducido, su bajo costo y porque nunca se ha documentado resistencia a este. ${ }^{16}$ En nuestro estudio se observó un uso de betalactámicos del 89,99\%, donde el mayor porcentaje $(61,87 \%)$ correspondió a amoxicilina, medicamento que por su espectro se recomienda más para infecciones de tracto respiratorio bajo (ej. Neumonía), mientras que el uso de penicilina benzatínica fue bajo (28,12\%) (Tabla 4 ) a pesar de que la resistencia por parte del SBHGA contra la penicilina benzatínica no se ha modificado, por lo que su uso debería promoverse en esta patología; para disminuir la tasa de resistencia en otras bacterias.

Actualmente se conoce que SBHGA ha desarrollado resistencia frente a macrólidos, por lo cual, su uso es justificado como fármaco de primera línea sólo en caso de alergia a betalactámicos. ${ }^{20}$ Esto, comparado con lo encontrado con nuestro estudio revela que aún se sigue evidenciando su uso $(8,12 \%)$ (Tabla 4) como fármaco de primera línea de manera no justificada, debido a que se espera que exista alergia a la penicilina en un $2 \%$ de la población ambulatoria. ${ }^{21}$

El uso inapropiado de antibióticos se refleja en nuestro estudio al ver que en los grupos de bajo riesgo de infección por el SBHGA se sigan prescribiendo antibióticos, a pesar de la baja prevalencia de esta infección bacteriana, y aún más la baja incidencia de sus complicaciones supurativas y no supurativas. Estos datos indican que existe un uso inapropiado de antibióticos en gran proporción de las atenciones a pacientes con faringoamigdalitis aguda, lo cual a largo plazo puede incurrir en altas tasas de resistencia a antibióticos e incluso, en un aumento de atenciones por efectos adversos relacionados a antibióticos. ${ }^{7}$

De acuerdo a un estudio realizado en la ciudad de Aragón, se evidenció tasas de prescripción de antibióticos del $75 \%$ en los episodios de faringoamigdalitis, ${ }^{17,19}$ lo cual es mayor a los datos encontrados en nuestro estudio (65,03\%).

Debido a la falta de estas pruebas microbiológicas, no se estudió el grupo de riesgo intermedio, por lo que sugerimos la realización de un estudio costo-beneficio para la evaluación de estas pruebas en los servicios de emergencia de primer nivel versus tratamientos empíricos.

Este estudio servirá como base para futuras investigaciones, y brindará datos sobre el uso inadecuado de antibióticos en pacientes atendidos en emergencia de centros de salud de primer nivel de atención, con la esperanza de disminuir la prescripción inadecuada de antibióticos en afecciones frecuentes como la faringoamigdalitis estreptocócica.

\section{Conclusiones}

Se encontró que el uso inadecuado de antibióticos es superior a la prevalencia estimada de faringoamigdalitis estreptocócica para el grupo de edad estudiado. Por esto, es imperativo que se tomen las medidas necesarias a nivel institucional y comunitario para lograr su reducción y evitar las complicaciones que se derivan de esta.

\section{Contribución de los autores}

Concepción y/o delineamiento del estudio: EPL, GB, PAS, e GWR. Recolección, análisis e interpretación de los datos: EPL, GB, PAS, e GWR. Redacción preliminar: EPL, GB, PAS, e GWR. Revisión crítica de la versión preliminar: EPL, GB, PAS, e GWR. Los autores aprobaron la versión final, y están de acuerdo con rendir cuentas sobre todos los aspectos del trabajo; siendo GR y AN los acrónimos del nombre de los autores. 


\title{
Conflicto de intereses
}

\author{
Ninguno declarado.
}

\section{Referencias}

1. Maguiña-Vargas C, Ugarte-Gil CA, Montiel M. Uso adecuado y racional de los antibióticos. Acta Médica Peruana. 2006;23(1):15-20.

2. Gaarslev C, Yee M, Chan G, Fletcher-Lartey S, Khan R. A mixed methods study to understand patient expectations for antibiotics for an upper respiratory tract infection. Antimicrob Resist Infect Control [Internet]. 2016;5(1):1-9. https://doi.org/10.1186/s13756-0160134-3

3. Timbrook TT, Caffrey AR, Ovalle A, Beganovic M, Curioso W, Gaitanis M, et al. Assessments of Opportunities to Improve Antibiotic Prescribing in an Emergency Department: A Period Prevalence Survey. Infect Dis Ther [Internet]. 2017;6(4):497-505. https://doi.org/10.1007/s40121-017-0175-9

4. Hildreth C, Burke A, Glass R. JAMA patient page. Inappropriate Use of Antibiotics. JAMA. 2009;302(7):816. https://doi.org/10.1001/ jama.302.7.816

5. Hashemi S, Nasrollah A, Rajabi M. Irrational antibiotic prescribing: a local issue or global concern? EXCLI J. 2013;12:384-95.

6. Pignatari ACC, Myake MM. The inappropriate use of antibiotics in upper respiratory tract infections: It is time for action. Braz $\mathrm{J}$ Otorhinolaryngol [Internet]. 2016;82(2):121-2. https://doi.org/10.1016/j.bjorl.2015.12.003

7. Linder JA. Antibiotics for Treatment of Acute Respiratory Tract Infections: Decreasing Benefit, Increasing Risk, and the Irrelevance of Antimicrobial Resistance. Clin Infect Dis [Internet]. 2008;47(6):744-6. https://doi.org/10.1086/591149

8. Piñeiro Pérez R, Hijano Bandera F, Álvez González F, Fernández Landaluce A, Silva Rico JC, Pérez Cánovas C, et al. Documento de consenso sobre el diagnóstico y tratamiento de la faringoamigdalitis aguda. An Pediatr [Internet]. 2011;75(5):342.e1-342.e13. https://doi.org/10.1016/j.anpedi.2011.07.015

9. Shaikh N, Swaminathan N, Hooper EG. Accuracy and Precision of the Signs and Symptoms of Streptococcal Pharyngitis in Children: A Systematic Review. J Pediatr [Internet]. 2012;160(3):487-93.e3. https://doi.org/10.1016/j.jpeds.2011.09.011

10. Mclsaac WJ, White D, Tannenbaum D, Low DE. A clinical score to reduce unnecessary antibiotic use in patients with sore throat. CMAJ. 1998;158(1):75-83.

11. Cohen JF, Cohen R, Levy C, Thollot F, Benani M, Bidet P, et al. Selective testing strategies for diagnosing group A streptococcal infection in children with pharyngitis: a systematic review and prospective multicentre external validation study. CMAJ. 2015;187(1):2332. https://doi.org/10.1503/cmaj.140772

12. Gutiérrez D, León K, Bahamonde H. Faringoamigdalitis estreptocócica. Rev Hosp Clín Univ Chile. 2011;22(6):281-8.

13. Ministerio de Salud Pública del Ecuador. Tipologia para homologar establecimientos de salud por niveles de atención y servicios de apoyo del Sistema Nacional de Salud. Acuerdo Ministerial 5212 [Acesso 2019 Ago 27]. Disponible en: https://www.salud.gob.ec/catalogo-de-normas-politicas-reglamentos-protocolos-manuales-planes-guias-y-otros-del-msp/

14. Ministerio de Salud Pública del Ecuador. darwin5248 @ public.tableau.com [Internet]. Perfil de Morbilidad Ambulatoria $2016 ; 2016$. [acceso en 2017 Nov 22]. Disponible en: https://public.tableau.com/profile/darwin5248\#!/vizhome/Perfildemorbilidadambulatoria2016/Men?publish=yes

15. Shulman ST, Bisno AL, Clegg HW, Gerber MA, Kaplan EL, Lee G, et al. Clinical practice guideline for the diagnosis and management of group A streptococcal pharyngitis: 2012 update by the Infectious Diseases Society of America. Clin Infect Dis. 2012;55(10):e86102. https://doi.org/10.1093/cid/cis629

16. Malo S, Bjerrum L, Feja C, Lallana MJ, Poncel A, Rabanaque MJ. Prescripción antibiótica en infecciones respiratorias agudas en atención primaria. An Pediatr. 2015;82(6):412-6. https://doi.org/10.1016/j.anpedi.2014.07.016

17. LLapa Yuquilima LE, Luna Cajamarca JP, Macao Coronel MP. Prevalencia de faringoamigdalitis aguda estreptocócica mediante el test de detección rápida del antígeno de estreptococo beta hemolítico y los factores asociados en pacientes entre 5 - 19 años en el Centro de Salud No 1 julio - septiembre, Cuenca 2013 [Thesis]. Cuenca: Universidad de Cuenca; 2014.

18. Rimoin AW, Walker CLF, Hamza HS, Elminawi N, Ghafar HA, Vince A, et al. The utility of rapid antigen detection testing for the diagnosis of streptococcal pharyngitis in low-resource settings. Int J Infect Dis [Internet]. 2010;14(12):e1048-53. https://doi.org/10.1016/j. ijid.2010.02.2269

19. Ortega Guillén AE. Uso de los Macrólidos en infecciones pediátricas. Enf Enf Microbiol. 2010;30(4):134-8.

20. Guzmán A, Salinas J, Toche P, Afani A. Alergia a ß-lactámicos. Rev Chil Infect [Internet]. 2004;21(4):285-98. [acceso en 2017 Nov 22]. Disponible en: http://www.scielo.cl/pdf/rci/v21n4/art02.pdf 